\title{
Article \\ Electrosprayed Ethyl Cellulose Core-Shell Microcapsules for the Encapsulation of Probiotics
}

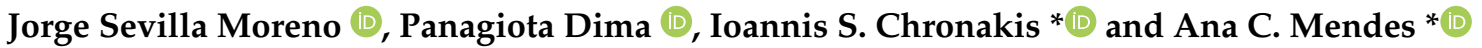 \\ DTU-Food, Research Group for Food Production Engineering, Laboratory of Nano-BioScience, \\ Technical University of Denmark, Kemitorvet B202, 2800 Kgs. Lyngby, Denmark; \\ jorgea.smoreno@gmail.com (J.S.M.); pandim@food.dtu.dk (P.D.) \\ * Correspondence: ioach@food.dtu.dk (I.S.C.); anac@food.dtu.dk (A.C.M.)
}

Citation: Moreno, J.S.; Dima, P. Chronakis, I.S.; Mendes, A.C. Electrosprayed Ethyl Cellulose Core-Shell Microcapsules for the Encapsulation of Probiotics. Pharmaceutics 2022, 14, 7 . https://doi.org/10.3390/ pharmaceutics14010007

Academic Editor: Juan José Torrado

Received: 18 November 2021

Accepted: 15 December 2021

Published: 21 December 2021

Publisher's Note: MDPI stays neutral with regard to jurisdictional claims in published maps and institutional affiliations.

Copyright: (C) 2021 by the authors. Licensee MDPI, Basel, Switzerland. This article is an open access article distributed under the terms and conditions of the Creative Commons Attribution (CC BY) license (https:// creativecommons.org/licenses/by/ $4.0 /)$.

\begin{abstract}
Electrosprayed ethyl cellulose core-shell microcapsules were produced for the encapsulation of probiotic Bifidobacterium animalis subsp. lactis (Bifido). Ethyl cellulose (ETC) was used as a shell material with different core compounds (concentrated Bifido, Bifido-maltodextrin and Bifido-glycerol). The core-shell microcapsules have an average diameter between $3 \mu \mathrm{m}$ and $15 \mu \mathrm{m}$ depending on the core compounds, with a distinct interface that separates the core and the shell structure. The ETC microcapsules displayed relatively low water activity (aw below 0.20 ) and relatively high values of viable cells $\left(10^{9}-10^{11} \mathrm{CFU} / \mathrm{g}\right)$, as counted post-encapsulation. The effect of different core compounds on the stability of probiotics cells over time was also investigated. After four weeks at $30{ }^{\circ} \mathrm{C}$ and $40 \% \mathrm{RH}$ the electrospray encapsulated samples containing Bifido-glycerol in the core showed a loss in viable cells of no more than $3 \log \operatorname{loss} \mathrm{CFU} / \mathrm{g}$, while the non-encapsulated Bifido lost about $7.57 \log \mathrm{CFU} / \mathrm{g}$. Overall, these results suggest that the viability of the Bifido probiotics encapsulated within the core-shell ETC electrosprayed capsules can be extended, despite the fact that the shell matrix was prepared using solvents that typically substantially reduce their viability.
\end{abstract}

Keywords: probiotics; cellulose derivatives; electrohydrodynamics; encapsulation; cell viability

\section{Introduction}

Probiotics are live microorganisms that are intended to have health benefits when consumed or applied to the body. Probiotics are generally sensitive to harsh environmental and processing conditions such as low $\mathrm{pH}$, digestive enzymes, heat treatment, water activity, and molecular oxygen. To ensure probiotics' healthy benefits, their metabolic activity has to be preserved in foods and during the complex digestive process until they reach the target site of the gastrointestinal tract (GIT) [1,2].

Probiotics' health benefits can be ensured by supplying a minimum of $10^{6}-10^{8} \mathrm{CFU}$ of live probiotics per gram of foodstuff [3]. Thus, probiotics need to be protected from the adverse conditions they are exposed to during food processing, storage, and the gastrointestinal digestion process. Encapsulation offers the possibility to preserve probiotics' viability from several harmful factors, and ensure their release at targeted sites in the digestive tract [4].

Several technologies are available for the encapsulation of probiotics in foods (e.g., spray-drying, spray-cooling, fluid-bed coating, extrusion, and complex coacervation followed by drying) [5]. Among all the main technologies, spray- and freeze-drying are the most common processes used in the food industry for the microencapsulation of active ingredients [5] including probiotics [2]. However, those technologies expose the probiotic cultures to harmful temperatures and pressures, which consequently cause a considerable reduction in bacterial viability [2].

Alternatively, electrospray stands out as a promising encapsulation technology of probiotics, producing dried nano-microcapsules from the breakup of a flowing liquid by means of an electrical field, at room temperature without heat, and without affecting 
the viability of the living cells [1]. Furthermore, it allows relatively high encapsulation efficiency [6], in addition to the possibility of using a broad range of capsule ingredients [7]. The functionality of electrosprayed capsules can be enhanced by the co-processing of biopolymer mixtures and by tuning their surface properties (e.g., crosslinking) [7] or by the utilization of co-axial electrospray methods to create core-shell structures [5].

Polysaccharides such as pullulan [8], alginate [6,9], starch-based ingredients [6,10], maltodextrin [11], and acacia gum [2] have been utilized as electrospray matrices to encapsulate probiotic cells with high encapsulation and stability efficiency.

For instance, Bifidobacterium animalis subsp. lactis $\mathrm{Bb} 12$ was encapsulated within electrosprayed capsules consisting of whey protein concentrate (WPC) and pullulan [8]. Lactobacillus acidophilus cells were encapsulated within electrosprayed core-shell alginate-zein microcapsules [9]. In another study, WPC was also used to encapsulate Lactobacillus plantarum [12] and freeze-dried Bifidobacterium longum subsp. infantis CECT 4552 [11].

Ethyl cellulose (ETC) is a linear polysaccharide produced by the replacement of the cellulose's hydroxyl end groups with ethyl end groups. ETC is non-water soluble and more hydrophobic than other commercial cellulose ethers [12], and it has been proved to be physiological inert, tasteless, odorless, non-caloric [13], non-toxic, and stable during storage [14,15], which makes it suitable for the encapsulation, protection, and delivery of bioactive compounds $[14,16]$. Commercially, ETC has been used in formulations conceived for oral and topical pharmaceutical applications including drug delivery and as a coating agent for tablets and granules to control the drug-release rate at the GIT track $[12,15,17]$.

Furthermore, it has been demonstrated that ETC can be used to produce electrospun fibers and electrosprayed capsules [14,16,18-22]. For instance, ketoprofen was encapsulated within electrosprayed ETC microparticles [14]. ETC with model hydrophilic components (vanillin, ethylmaltol, and maltol) was also included as core material in electrosprayed core-shell capsules, using stearic acid as a model lipid monolayer at the shell [16]. However, ETC has never been studied for the encapsulation of probiotic cells.

Based on the potential of ETC to be used as encapsulating material for bioactives, in this study electrosprayed core-shell ETC microcapsules were developed for the encapsulation and protection of Bifidobacterium animalis subsp. lactis (Bifido) probiotic cells. Different compounds (concentrated Bifido cells, Bifido-maltodextrin and Bifido-glycerol) were included within the microcapsule core. ETC microcapsules' functionality to preserve the viability of the encapsulated Bifido probiotics was evaluated.

\section{Materials and Methods}

\subsection{Materials}

All chemicals and materials used in this study, including ethyl cellulose (48.0-49.5\% $(w / w)$ ethoxy groups, degree of substitution of 2.5 [17], viscosity $30-70 \mathrm{mPa} . \mathrm{s}, 5 \%$ in toluene/ethanol 80:20 $\left(25^{\circ} \mathrm{C}\right)$ ), and glycerol were acquired from Sigma-Aldrich (Steinheim, Germany) unless otherwise indicated. The chemicals were used as received. Maltodextrin, with a commercial name of GLUCIDEX®12 (dextrose equivalent of 12, Mw of $23 \mathrm{kDa}$ [23]) was obtained from Roquette (Lestrem, France).

\subsection{Bacteria Culture}

Bifidobacterium animalis subsp. lactis (Bifido) (strain deposit number DSM 33443) was selected as the model strain supplied by Chr Hansen A/S (Hørsholm, Denmark). The strain was subjected to freeze pelletization, and stored at $-80^{\circ} \mathrm{C}$.

\subsection{Electrospray Solutions Preparation}

The electrospray shell solution was prepared by dissolving $8 \% w / v$ of ETC in ethanol $96 \%$ (VWR International, Darmstadt, Germany) or $8 \% w / v$ of ETC in acetone. The core solutions were prepared after thawing the Bifido cells at ambient conditions and mixing them with the different compounds (Table 1). For S2, $22.5 \mathrm{~mL}$ of thawed Bifido was gently added to a maltodextrin solution prepared by dissolving $30 \mathrm{~g}$ of maltodextrin in $35 \mathrm{~mL}$ of 
Mili-Q water. The core solutions of S3 and S4 were prepared by adding $30 \mathrm{~mL}$ of thawed Bifido mixed with $13 \mathrm{~mL}$ of glycerol.

Table 1. Sample designation for the different core-shell microcapsules made of ethyl cellulose in the shell.

\begin{tabular}{ccc}
\hline Sample Designation & Solvent in Shell & Core Composition \\
\hline S1 & Ethanol & Bifido \\
S2 & Ethanol & Bifido-maltodextrin \\
S3 & Ethanol & Bifido-glycerol \\
S4 & Acetone & Bifido-glycerol \\
\hline
\end{tabular}

\subsection{Co-Axial Electrospray of ETC Core-Shell Capsules Encapsulating Bifido}

The electrospray setup included: (i) two syringe pumps (New Era Pump Systems, Inc., Farmingdale, NY, USA), each one feeding the shell and the core solution at the flow rate of $0.42 \mathrm{~mL} / \mathrm{min}$ and $0.21 \mathrm{~mL} / \mathrm{min}$ to the co-axial needle, respectively (concentric needles with an inner diameter of $1.42 \mathrm{~mm}$ for shell solution and $0.48 \mathrm{~mm}$ for core solution), and (ii) a high voltage generator (ES50P-10W, Gamma High Voltage Research, Inc., Ormond Beach, FL, USA) was utilized to provide an applied voltage of $+30 \mathrm{kV}$ at the co-axial needle and an applied voltage of $-5 \mathrm{kV}$ at the collector. The distance from the co-axial needle to the collector was $10 \mathrm{~cm}$. The electrospraying process was performed in a fume hood to keep the process under $30 \%$ relative humidity using nitrogen. The collected capsules were them removed from the collector and stored at $-80{ }^{\circ} \mathrm{C}$ prior further analysis.

\subsection{Microscopy Analysis}

The size and morphology of the electrosprayed ETC core-shell capsules and free Bifido were investigated using a scanning electron microscope (SEM). Free Bifido samples were fixed with glutaraldehyde (Electron Microscopy Sciences, Hatfield, PA, USA) solution $(2.5 \%, v / v$ in $0.1 \mathrm{M}$ phosphate-buffered solution, $\mathrm{pH} 7.4)$ for $1 \mathrm{~h}$. The samples were then dehydrated in a graded ethanol series (50,70, 90, 96, and 100\%) followed by immersion in hexamethyldisilazane (HMDS). Samples (free Bifido and ETC core-shell capsules loaded with Bifido) were coated with $6 \mathrm{~nm}$ of gold for better conductivity using a sputter coater (Leica Coater ACE 200, Leica, Vienna, Austria) and imaged in a Quanta FEG 3D SEM (FEI, Eindhoven, Netherlands). The microcapsule diameter was calculated using Image J analysis software (National Institutes of Health, Bethesda, MD, USA), by measuring 50 different capsule diameters for each sample. The average diameter was calculated from these measurements for each microcapsule.

To evaluate probiotics distribution inside the capsules, the microcapsules with encapsulated Bifido cells were dispersed in $\mathrm{NaCl}$ 0.9\%. Incubation with RedDot (Biotium, Fremont, CA, USA) at $37{ }^{\circ} \mathrm{C}$ for $10 \mathrm{~min}$ protected from light was performed prior to visualization using an Axioplan Imager Z1m microscope (Zeiss, Oberkochen, Germany).

\subsection{Fourier Transform Infrared Spectroscopy (FT-IR)}

FTIR spectra of the core-shell microcapsules loading Bifido and free Bifido cells were obtained using a FTIR spectrometer (Spectrum 100, FT-IR spectrometer, Perkin Elmer, Waltham, MA, USA). The FTIR spectra were acquired at a wavelength ranging from $4.000 \mathrm{~cm}^{-1}$ to $650 \mathrm{~cm}^{-1}$ at room temperature $\left(20 \pm 2{ }^{\circ} \mathrm{C}\right)$. Each measurement was derived an average from 4 scans.

\subsection{Water Activity (aw)}

The water activity (aw) of the ETC-Bifido microcapsules was measured using a water activity analyzer (LabMaster-aw basic, Novasina, Lachen, Switzerland), at $25^{\circ} \mathrm{C}$. 


\subsection{Cell Viability, Encapsulation Efficiency, and Storage Stability}

Electrosprayed samples containing Bifidobacterium animalis were stored in a desiccant cabinet, (NALGENE ${ }^{\circledR}$ 5317-0120, Thermo Fisher Scientific ${ }^{\mathrm{TM}}$, Rochester, NY, USA), containing a saturated solution of potassium carbonate at a relative humidity $(\mathrm{RH})$ of $40 \%$ at $30{ }^{\circ} \mathrm{C}$. The viability of encapsulated and non-encapsulated Bifido cells was determined by colony-forming unit (CFU) analysis. The samples were diluted 1:100 with Maximum Recovery Diluent (MRD, (Oxoid CM0733, Hampshire, UK)) at $37^{\circ} \mathrm{C}$.

The suspension was homogenized by stomaching (Smasher, AES Laboratoire, bioMérieux, Hazelwood, MO, USA) at intermediate speed for $2 \mathrm{~min}$, and further dilutions were performed in MRD. Appropriate volumes of appropriate dilutions were plated in de Man Rogosa Sharpe (MRS) agar supplemented with 0.05 w/v \% L-cysteine hydrochloride monohydrate by pour plating, aiming for colony counts between 30-300 CFU/plate. Plates were incubated at $37^{\circ} \mathrm{C}$ under anaerobic conditions for 3 days, and the results were calculated as the average of 2 plates. Cell viability was measured at the time points of 0,2 , and 4 weeks.

The encapsulation efficiency (EE) of the microcapsules was calculated by determining the number of viable cells inside the capsules $(\mathrm{N})$ divided by the number of viable cells in the initial solution (N0), as expressed in (1) [2]:

$$
\mathrm{EE}(\%)=\frac{\log \mathrm{N}}{\log \mathrm{N} 0} \times 100
$$

\subsection{Data Analysis}

Student's $t$-test was applied to determine statistical significance using Excel software. One-tailed unpaired t-test with $95 \%$ confidence interval was considered statistically significant if $p<0.05\left(^{*}\right)$.

\section{Results and Discussion}

\subsection{Microcapsules and Cells Size and Morphology}

The Bifido cells used in this study displayed a typical rod-like structure, with an average length of about 1-1.5 $\mu \mathrm{m}$ as observed by SEM (Figure 1), which is in agreement with previous studies [24].
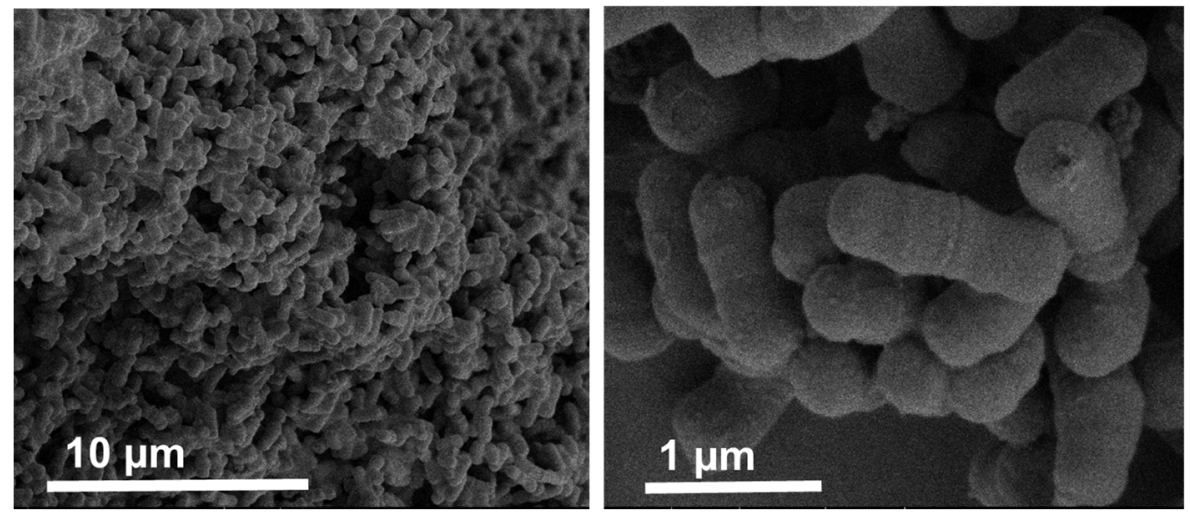

Figure 1. SEM images of free Bifido cells at different magnifications.

The size and the morphology of the electrosprayed ETC core-shell capsules loaded with Bifido are shown in Figure 2. Overall, the core-shell microcapsules revealed a dimpled structure morphology, which resembles the morphology of electrosprayed ETC-based capsules [14]. The lack of spherical structure of these particles could be related with the fast evaporation of the solvent, as both ethanol and acetone are highly volatile solvents. Electrosprayed capsules with smoother and spherical-like surfaces can be obtained using solvents with a lower evaporation rate [25]. 

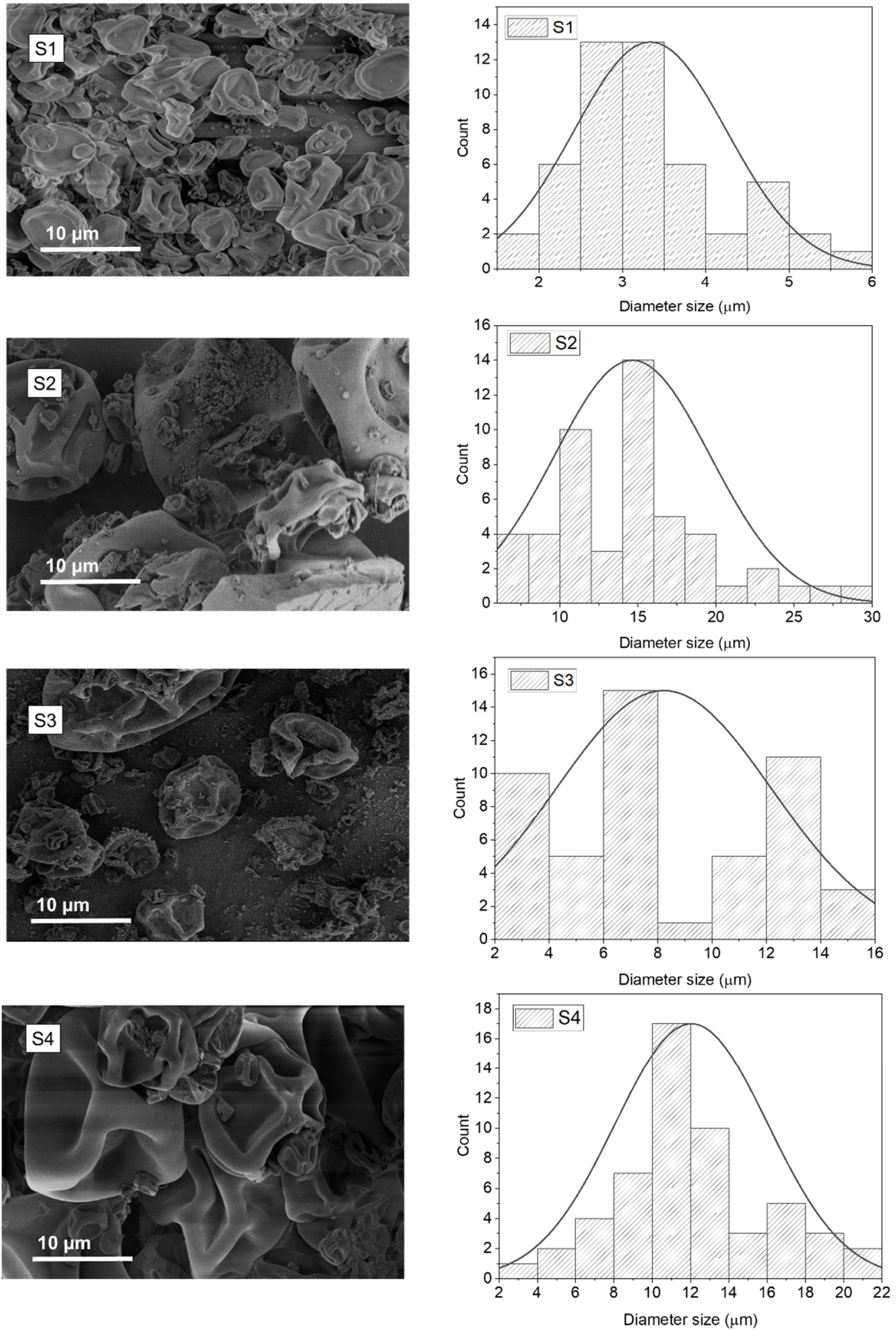

Figure 2. SEM images of ETC core-shell capsules loading Bifido (samples S1-S4) and respective histograms displaying microcapsules diameter distribution.

The electrosprayed core-shell capsules that contain only Bifido in the core (S1), displayed an average diameter of $3.33 \pm 1.18 \mu \mathrm{m}$ (Table 2). However, when maltodextrin (S2) and glycerol (S3) were incorporated in the microcapsule core, the average diameter of the 
capsules was increased to $14.63 \pm 4.99$ and $8.21 \pm 3.96 \mu \mathrm{m}$, respectively (Table 2$)$. This could be due to the increase in the viscosity of the core solution.

Table 2. Average diameter, water activity (aw), and encapsulation efficiency (EE) of the electrosprayed ETC core-shell microcapsules loading Bifido cells.

\begin{tabular}{ccccc}
\hline $\begin{array}{c}\text { Sample } \\
\text { Designation }\end{array}$ & $\begin{array}{c}\text { Diameter Size } \\
/ \mu \mathrm{m}\end{array}$ & PDI & aw & EE\% \\
\hline S1 & $3.33 \pm 1.18^{*}$ & 0.083 & $0.13 \pm 0.028$ & 39.6 \\
S2 & $14.63 \pm 4.99 *$ & 0.12 & $0.16 \pm 0.010$ & 44.8 \\
S3 & $8.21 \pm 3.96^{*}$ & 0.23 & $0.20 \pm 0.029$ & 77.6 \\
S4 & $12.04 \pm 3.98^{*}$ & 0.09 & $0.18 \pm 0.066$ & 87.4 \\
\hline * All values are mean + standard deviation * indicates significant difference $(p<0.05)$
\end{tabular}

${ }^{*}$ All values are mean \pm standard deviation. ${ }^{*}$ indicates significant difference $(p<0.05)$.

An increase in the average diameter of the microcapsules was also observed when acetone was used as ETC solvent (S4), in comparison to the capsules prepared using ethanol (S3) (Figure 2 and Table 2). Furthermore, the higher average diameter determined for S4 comparatively to S3 could be probably due to the higher polydispersity of the microcapsules size produced with ethanol (S3) (Table 2) and due to the higher encapsulation efficiency of cells in sample $\mathrm{S} 4$.

Figure 3 shows a cross-section of core-shell electrosprayed ETC capsules prepared with acetone as the shell solvent (S4). A distinct interface that separates the core of the capsule (containing the Bifido cells imbedded in glycerol) from the ETC shell can be observed. Thus, it is presumed that fast outer shell solvent evaporation (in this case acetone) and subsequent shell solidification prevents the diffusion and mixing of the core and shell compounds. A distinct interface between the core and the shell was also noticed in a previous study of core-shell electrospun starch fibers for the encapsulation of probiotics [10].
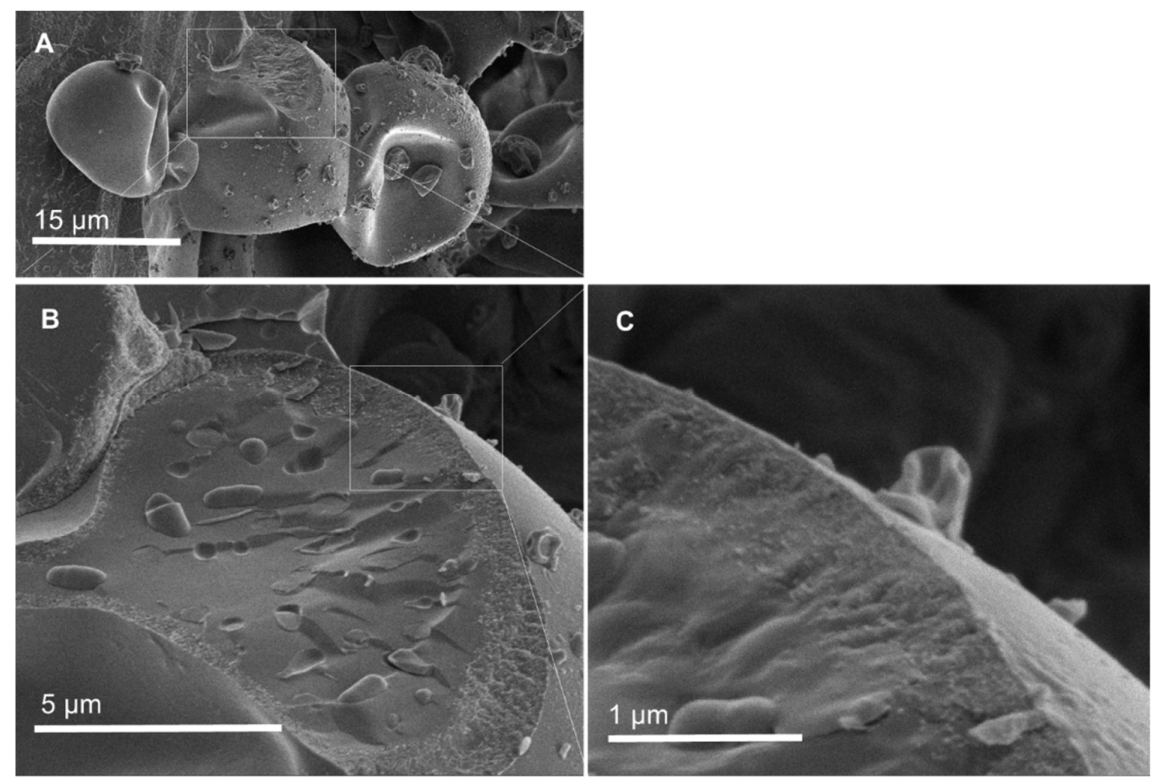

Figure 3. SEM images showing the overall structure of electrosprayed ETC core-shell microcapsules loading Bifido: (A) the microcapsule cross-section with (B) the distinct core and shell materials, and the Bifido cells distributed within the core of the microcapsules; (C) the interface between ETC (shell) and glycerol (core).

To study the distribution of the encapsulated cells within the microcapsules, the cells were stained and analyzed using confocal microscopy. Figure 4 confirms that the Bifido cells were effectively encapsulated and homogeneously distributed within the different ETC core-shell microcapsules. 

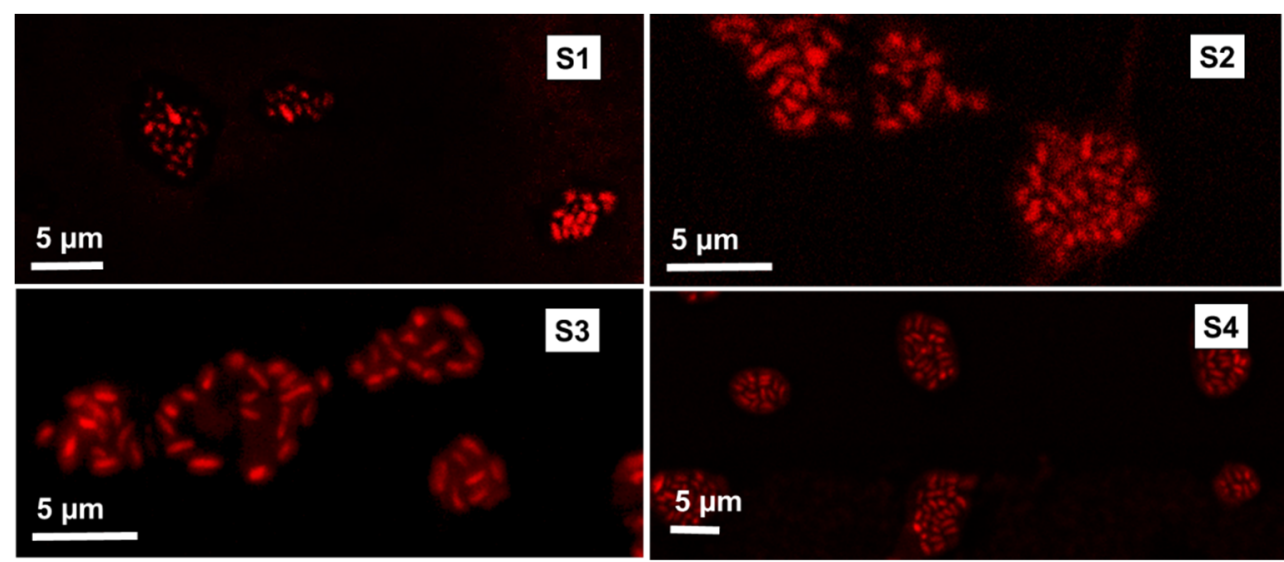

Figure 4. Confocal microscopy images of the Bifido encapsulated within the electrosprayed ETC core-shell microcapsules.

\subsection{Water Activity (aw)}

The composition of the capsule, the permeability of oxygen, and the aw are key parameters to preserve the viability of probiotic cells [3]. In respect to the aw, the optimal survival of probiotic cells occurs at aw $<0.3$ [26], where probiotics can maintain their functionality after drying. The aw of the electrosprayed ETC-Bifido microcapsules ranged from 0.13 to 0.20 (Table 2).

When ethanol was used as the ETC solvent for the microcapsule shell, the water activity increased in the order S1 $<$ S2 $<$ S3 (not statistically significant). The slightly higher water activity of the sample S2 comparatively to S1 could be attributed to the presence of hydrophilic maltodextrin, which increases the affinity for water binding. The highest value of aw was found for S3, most likely due to the hydrogen bonding and molecular dynamics of the water of the aqueous dispersion of Bifido-glycerol mixtures in the core [27], which is in agreement with FTIR results (Figure 5).

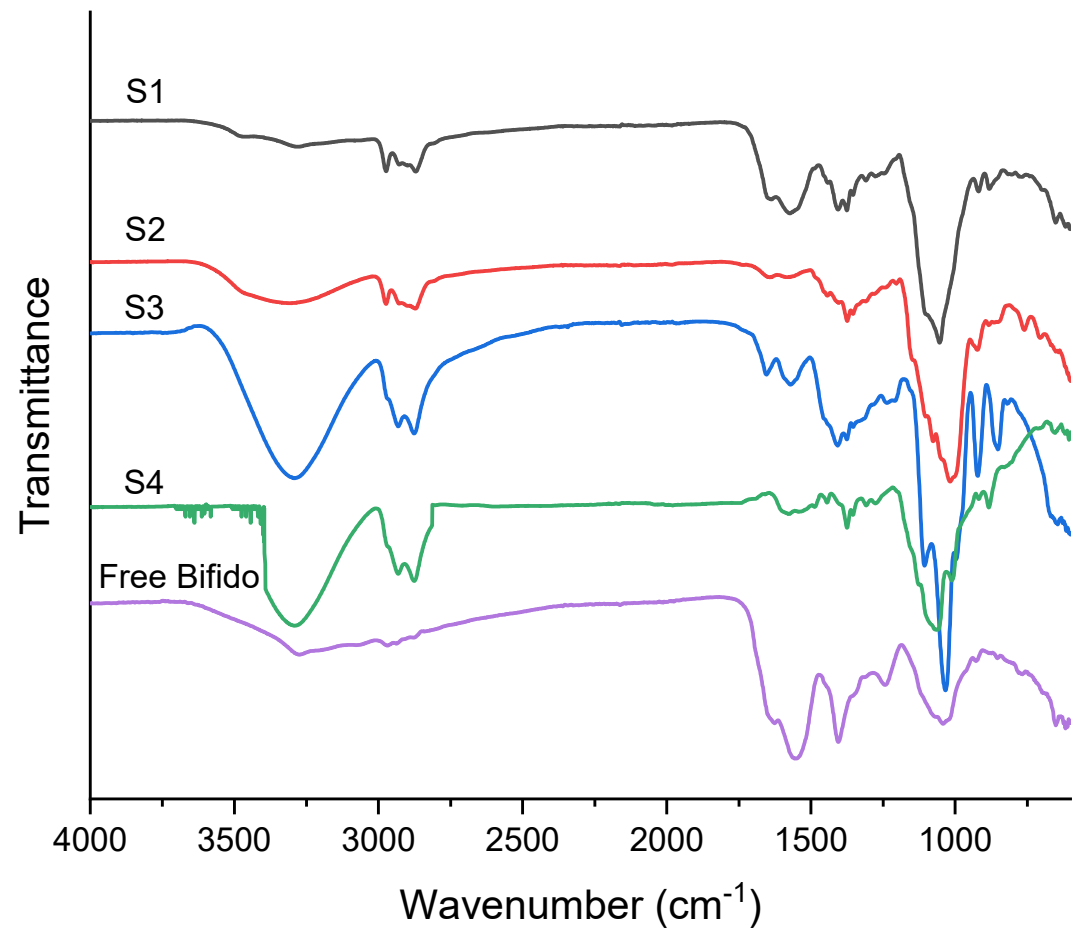

Figure 5. FTIR spectra of Bifido cells encapsulated within electrosprayed ETC core-shell microcapsules, and non-encapsulated (free) Bifido. 


\subsection{FTIR}

The FTIR spectra of free Bifido (Figure 5) shows three distinct bands at 3208, 1629, and $1550 \mathrm{~cm}^{-1}$ corresponding to amide groups of the existing proteins at the cell membrane. Furthermore, the bands at 2968,2973 , and $2878 \mathrm{~cm}^{-1}$ are mainly attributed to the asymmetric stretches of methyl and methylene groups of the lipid components of the membrane, mainly fatty acids, as also suggested elsewhere [28,29]. Furthermore, a band at $1401 \mathrm{~cm}^{-1}$ could be related to the $(\mathrm{C}-\mathrm{O})$ vibrations of $\mathrm{COO}$ - groups from esterified lipids and fatty acids [28]. The bands assigned at 1244 and $1043 \mathrm{~cm}^{-1}$ are provided by the $(\mathrm{P}=\mathrm{O}) \mathrm{s}$ of $\mathrm{PO}^{2-}$ groups [30].

The shell compound of the microcapsules was ethyl cellulose, and consequently a distinct peak at $3464 \mathrm{~cm}^{-1}$ was observed, due to the -OH groups of the polysaccharide backbone [14]. The intra- and intermolecular hydrogen bonding due to the -OH groups is more intense for the samples containing glycerol (S3 and S4). The asymmetric peaks of $-\mathrm{CH}$ stretching can be seen in the peak regions of $2970-2870 \mathrm{~cm}^{-1}$. Other relevant vibration peaks around 1054-1011 and $1275 \mathrm{~cm}^{-1}$ were mainly attributed to C-O-C stretch and C-H bending, respectively [30]. It is important to note that the C-O-C stretch does not display the same absorption wavenumber, probably due to changes in the bond strength and force constant of $\mathrm{C}-\mathrm{O}-\mathrm{C}$ bond related with the different solvents.

\subsection{Cell Viability and Stability over Time}

Figure 6 displays the number of viable cells determined by the plate counting method post-encapsulation. Furthermore, free Bifido viable cells (non-encapsulated) were also determined and displayed an initial cell count of $11.10 \mathrm{log}$ CFU/g. The encapsulation efficiency (EE) determined for viable cells encapsulated within ETC electrosprayed microcapsules was about $39.6,44.8,77.6$, and $87.41 \%$, for S1, S2, S3, and S4, respectively (Table 2).

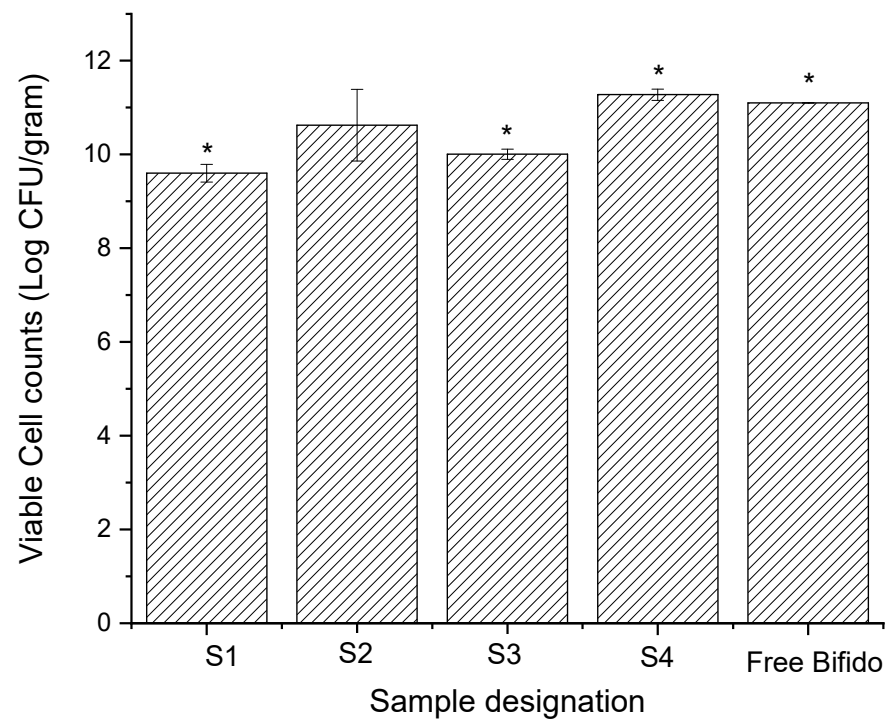

Figure 6. Viable cell counts post-encapsulation of Bifido probiotic cells encapsulated within electrosprayed ETC core-shell microcapsules and non-encapsulated (free) Bifido. All values are mean \pm standard deviation, and * indicates a significant difference $(p<0.05)$.

For the samples prepared using ethanol as a shell solvent (S1-S3), S1 displayed the lowest value of viable probiotics at $9.62 \log \mathrm{CFU} / \mathrm{g}$. The number of viable encapsulated probiotics for S2 and S3 was about $10.90 \log \mathrm{CFU} / \mathrm{g}$ and $10.01 \log \mathrm{CFU} / \mathrm{g}$, respectively. The increase in the initial viable cells counts of the sample S2 in comparison to S1 suggests that maltodextrin has some protective effect on Bifido (note the similar encapsulation efficiency of these samples). Sample S4 (ETC shell electrosprayed using acetone), showed slightly higher cell viability counts (11.28 log CFU/g) in respect to S3 (ETC shell electrosprayed 
using ethanol). The higher number of viable encapsulated probiotics detected in S3 and $S 4$, in respect to S1, could be due to the higher initial cells number, the higher EE, and also due to the protection of the glycerol core compound. Overall, these results suggest that the probiotic cells encapsulated within the core-shell ETC electrosprayed capsules preserved their viability after electrospraying, despite the fact that the shell matrix was prepared using solvents that typically substantially reduce their viability. This further confirms that the solvent of the shell matrix (ETC) did not migrate into the core of the microcapsules during electrospray processing, where the probiotics were mostly located (Figure 3).

Due to the higher encapsulation efficiency obtained for samples S3 and S4, their stability over time was also assessed using plate counting $\left(30^{\circ} \mathrm{C}\right.$ and $\left.40 \% \mathrm{RH}\right)$ and compared with non-encapsulated Bifido cells (free Bifido) (Figure 7). In the first two weeks of the stability study, a reduction in the viable cells from $10.01 \mathrm{log}$ CFU/g to $9.13 \mathrm{log}$ CFU/g was observed for S3. Cells encapsulated in S4 showed a reduction from 11.28 to $9.16 \log \mathrm{CFU} / \mathrm{g}$.

A)

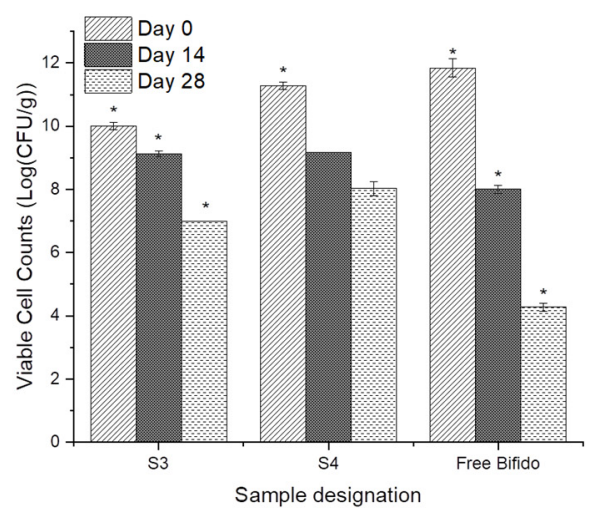

B)

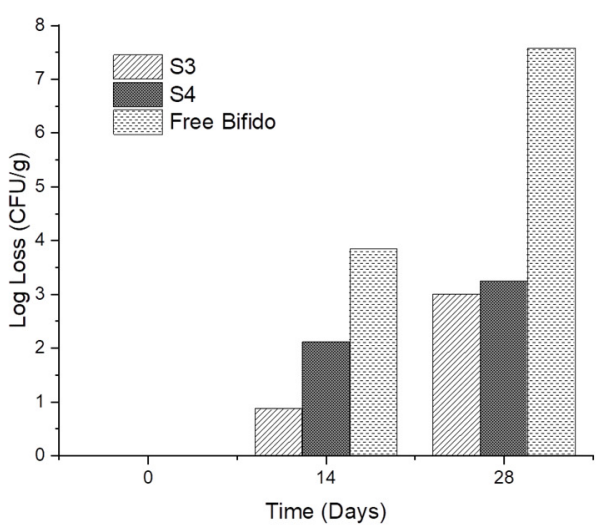

Figure 7. Viable cell counts (A) and log loss of viability (B) over time $\left(30^{\circ} \mathrm{C}\right.$ and $\left.40 \% \mathrm{RH}\right)$ of encapsulated Bifido within electrosprayed ETC core-shell microcapsules, and non-encapsulated (free) cells. All values are mean \pm standard deviation, and * indicates significant difference $(p<0.05)$.

The non-encapsulated Bifido cells lost about 3.84 log CFU/g of their viability, within two weeks, and showed a log loss of $7.57 \mathrm{CFU} / \mathrm{g}$ after four weeks at $30{ }^{\circ} \mathrm{C}$ and $40 \%$ RH. The electrospray encapsulated Bifido cells only lost about $3 \mathrm{log} \mathrm{CFU} / \mathrm{g}$ of viable cells (Figure 7B). Previous studies also suggested that glycerol has a protective effect on probiotics' stability $[10,31,32]$.

\section{Conclusions}

Electrosprayed ethyl-cellulose core-shell microcapsules were produced for the encapsulation of Bifido probiotic cells. The average diameter of the core-shell capsules was between $3 \mu \mathrm{m}$ and approximately 15. A distinct shell and core microstructure were observed, indicating that the shell matrix of ETC and the solvent did not migrate into the core of the capsule, where the probiotics were mostly located. The core-shell microcapsules of ETC displayed a relatively low aw (below 0.20 ) and relatively high values of viable cells $\left(10^{9}-10^{11} \mathrm{CFU} / \mathrm{g}\right)$ counted post-encapsulation. After four weeks at $30^{\circ} \mathrm{C}$ and $40 \% \mathrm{RH}$, the encapsulated samples contained Bifido-glycerol in the core, showed a loss in viable cells no more than $3 \log \mathrm{CFU} / \mathrm{g}$, while the non-encapsulated Bifido lost about $7.57 \log$ $\mathrm{CFU} / \mathrm{g}$. Overall, the present study clearly demonstrates the potential of electrosprayed ETC core-shell microcapsules to encapsulate probiotic cells and to extend their viability over time.

Author Contributions: Conceptualization, A.C.M. and I.S.C.; methodology, J.S.M., P.D., A.C.M., and I.S.C.; formal analysis, A.C.M. and I.S.C.; investigation, J.S.M., P.D.; A.C.M., and I.S.C.; writingoriginal draft preparation, A.C.M.; writing-review and editing, A.C.M. and I.S.C.; supervision, A.C.M. and I.S.C.; All authors have read and agreed to the published version of the manuscript. 
Funding: This research was funded by the Innovation Fund Denmark (PROBIO project number 7076-00053B).

Institutional Review Board Statement: Not applicable.

Informed Consent Statement: Not applicable.

Data Availability Statement: Not applicable.

Acknowledgments: The authors thank Chr-Hansen A/S for the valuable discussions.

Conflicts of Interest: Authors declare that there is no conflict of interest.

\section{References}

1. Mendes, A.C.; Chronakis, I.S. Electrohydrodynamic Encapsulation of Probiotics: A Review. Food Hydrocoll. 2021, 117, 106688. [CrossRef]

2. Zaeim, D.; Sarabi-Jamab, M.; Ghorani, B.; Kadkhodaee, R.; Tromp, R.H.H. Electrospray-Assisted Drying of Live Probiotics in Acacia Gum Microparticles Matrix. Carbohydr. Polym. 2018, 183, 183-191. [CrossRef]

3. Jiménez, M.; Flores-Andrade, E.; Pascual-Pineda, L.A.; Beristain, C.I. Effect of Water Activity on the Stability of Lactobacillus Paracasei Capsules. LWT_Food Sci. Technol. 2015, 60, 346-351. [CrossRef]

4. Chávarri, M.; Marañón, I.; Villarán, M.C. Encapsulation Technology to Protect Probiotic Bacteria. Probiotics 2012, 501-540. [CrossRef]

5. García-Moreno, P.J.; Mendes, A.C.; Jacobsen, C.; Chronakis, I.S. Biopolymers for the Nano-Microencapsulation of Bioactive Ingredients by Electrohydrodynamic Processing; Springer: Cham, Switzerland, 2018; ISBN 9783319946252.

6. Pitigraisorn, P.; Srichaisupakit, K.; Wongpadungkiat, N.; Wongsasulak, S. Encapsulation of Lactobacillus Acidophilus in MoistHeat-Resistant Multilayered Microcapsules. J. Food Eng. 2017, 192, 11-18. [CrossRef]

7. Mendes, A.C.; Stephansen, K.; Chronakis, I.S. Electrospinning of Food Proteins and Polysaccharides. Food Hydrocoll. 2017, 68, 53-68. [CrossRef]

8. López-Rubio, A.; Sanchez, E.; Wilkanowicz, S.; Sanz, Y.; Lagaron, J.M. Electrospinning as a Useful Technique for the Encapsulation of Living Bifidobacteria in Food Hydrocolloids. Food Hydrocoll. 2012, 28, 159-167. [CrossRef]

9. Laelorspoen, N.; Wongsasulak, S.; Yoovidhya, T.; Devahastin, S. Microencapsulation of Lactobacillus Acidophilus in Zein-Alginate Core-Shell Microcapsules via Electrospraying. J. Funct. Foods 2014, 7, 342-349. [CrossRef]

10. Lancuški, A.; Abu Ammar, A.; Avrahami, R.; Vilensky, R.; Vasilyev, G.; Zussman, E. Design of Starch-Formate Compound Fibers as Encapsulation Platform for Biotherapeutics. Carbohydr. Polym. 2017, 158, 68-76. [CrossRef]

11. Librán, C.M.M.; Castro, S.; Lagaron, J.M.M. Encapsulation by Electrospray Coating Atomization of Probiotic Strains. Innov. Food Sci. Emerg. Technol. 2017, 39, 216-222. [CrossRef]

12. Arca, H.C.; Mosquera-Giraldo, L.I.; Bi, V.; Xu, D.; Taylor, L.S.; Edgar, K.J. Pharmaceutical Applications of Cellulose Ethers and Cellulose Ether Esters. Biomacromolecules 2018, 19, 2351-2376. [CrossRef]

13. Davidovich-Pinhas, M.; Barbut, S.; Marangoni, A.G. Physical Structure and Thermal Behavior of Ethylcellulose. Cellulose 2014, 21, 3243-3255. [CrossRef]

14. Huang, L.Y.; Yu, D.G.; Branford-White, C.; Zhu, L.M. Sustained Release of Ethyl Cellulose Micro-Particulate Drug Delivery Systems Prepared Using Electrospraying. J. Mater. Sci. 2012, 47, 1372-1377. [CrossRef]

15. Wasilewska, K.; Winnicka, K. Ethylcellulose-a Pharmaceutical Excipient with Multidirectional Application in Drug Dosage Forms Development. Materials 2019, 12, 3386. [CrossRef]

16. Eltayeb, M.; Stride, E.; Edirisinghe, M. Electrosprayed Core-Shell Polymer-Lipid Nanoparticles for Active Component Delivery. Nanotechnology 2013, 24, 465604. [CrossRef]

17. Brady, J.; Du, T.; Lee, I.; Li, J. Polymer Properties and Characterization; Academic Press: Cambridge, MA, USA, 2017; ISBN 9780128024478.

18. Wu, X.; Wang, L.; Yu, H.; Huang, Y. Effect of Solvent on Morphology of Electrospinning Ethyl Cellulose Fibers. J. Appl. Polym. Sci. 2005, 97, 1292-1297. [CrossRef]

19. Zhao, S.; Wu, X.; Wang, L.; Huang, Y. Electrospinning of Ethyl-Cyanoethyl Cellulose / Tetrahydrofuran Solutions. J. Appl. Polym. Sci. 2003, 91, 242-246. [CrossRef]

20. Li, C.; Wang, Z.H.; Yu, D.G.; Williams, G.R. Tunable Biphasic Drug Release from Ethyl Cellulose Nanofibers Fabricated Using a Modified Coaxial Electrospinning Process. Nanoscale Res. Lett. 2014, 9, 258. [CrossRef]

21. Zaitoon, A.; Lim, L.T. Effect of Poly(Ethylene Oxide) on the Electrospinning Behavior and Characteristics of Ethyl Cellulose Composite Fibers. Materialia 2020, 10, 100649. [CrossRef]

22. Niu, B.; Zhan, L.; Shao, P.; Xiang, N.; Sun, P.; Chen, H.; Gao, H. Electrospinning of Zein-Ethyl Cellulose Hybrid Nanofibers with Improved Water Resistance for Food Preservation. Int. J. Biol. Macromol. 2020, 142, 592-599. [CrossRef]

23. Kutzli, I.; Beljo, D.; Gibis, M.; Baier, S.K.; Weiss, J. Effect of Maltodextrin Dextrose Equivalent on Electrospinnability and Glycation Reaction of Blends with Pea Protein Isolate. Food Biophys. 2020, 15, 206-215. [CrossRef] 
24. Kang, C.H.; Han, S.H.; Kim, J.S.; Kim, Y.; Jeong, Y.; Park, H.M.; Paek, N.S. Inhibition of Nitric Oxide Production, Oxidative Stress Prevention, and Probiotic Activity of Lactic Acid Bacteria Isolated from the Human Vagina and Fermented Food. Microorganisms 2019, 7, 109. [CrossRef]

25. Nguyen, D.N.; Clasen, C.; Van den Mooter, G. Pharmaceutical Applications of Electrospraying. J. Pharm. Sci. 2016, 105, 2601-2620. [CrossRef] [PubMed]

26. Verruck, S.; de Liz, G.R.; Dias, C.O.; de Mello Castanho Amboni, R.D.; Prudencio, E.S. Effect of Full-Fat Goat's Milk and Prebiotics Use on Bifidobacterium BB-12 Survival and on the Physical Properties of Spray-Dried Powders under Storage Conditions. Food Res. Int. 2019, 119, 643-652. [CrossRef]

27. Nakagawa, H.; Oyama, T. Molecular Basis of Water Activity in Glycerol-Water Mixtures. Front. Chem. 2019, 7, 731. [CrossRef]

28. Vodnar, D.C.; Socaciu, C.; Rotar, A.M.; Stãnilã, A. Morphology, FTIR Fingerprint and Survivability of Encapsulated Lactic Bacteria (Streptococcus Thermophilus and Lactobacillus Delbrueckii Subsp. Bulgaricus) in Simulated Gastric Juice and Intestinal Juice. Int. J. Food Sci. Technol. 2010, 45, 2345-2351. [CrossRef]

29. Trivedi, M.K.; Branton, A.; Trivedi, D.; Nayak, G.; Mishra, R.K.; Jana, S. Characterization of Physicochemical and Thermal Properties of Biofield Treated Ethyl Cellulose and Methyl Cellulose. Int. J. Biomed. Mater. Res. 2015, 3, 83-91. [CrossRef]

30. Santos, M.; Gerbino, E.; Tymczyszyn, E.; Gomez-Zavaglia, A. Applications of Infrared and Raman Spectroscopies to Probiotic Investigation. Foods 2015, 4, 283-305. [CrossRef]

31. Huq, T.; Khan, A.; Khan, R.A.; Riedl, B.; Lacroix, M. Encapsulation of Probiotic Bacteria in Biopolymeric System. Crit. Rev. Food Sci. Nutr. 2013, 53, 909-916. [CrossRef]

32. Terpou, A.; Papadaki, A.; Lappa, I.K.; Kachrimanidou, V.; Bosnea, L.A.; Kopsahelis, N. Probiotics in Food Systems: Significance and Emerging Strategies Towards Improved Viability and Delivery of Enhanced Beneficial Value. Nutrients 2019, $11,1591$. [CrossRef] 